Revista Científica do Corpo de Bombeiros Militar de Pernambuco

XVIII Seminário Nacional de Bombeiros - Foz do Iguaçu PR

Vol.04 No11 - Edição Especial XVIII SENABOM - ISSN 2359-4829

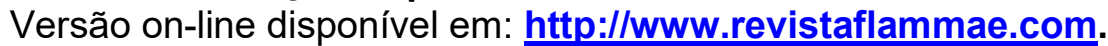

\title{
A EDUCAÇÃO AMBIENTAL COMO FERRAMENTA NA PREVENÇÃO DE INCÊNDIOS FLORESTAIS
}

\author{
LA EDUCACIÓN AMBIENTAL COMO HERRAMIENTA EN LA PREVENCIÓN DE \\ INCENDIOS FORESTALES
}

\author{
Alexandre Mançano Cavalca ${ }^{1}$ \\ Luisiana Guimarães Cavalca ${ }^{2}$
}

\section{Resumo}

Este trabalho teve como objetivo mostrar a importância da formação de uma consciência ambiental na população, através da educação, visando a prevenção contra os incêndios florestais. Realizou-se uma pesquisa bibliográfica, demonstrando através de dados estatísticos que grande parte dos incêndios florestais ocorre por causas humanas, assim este artigo visou demonstrar a utilização da educação ambiental como ferramenta de trabalho para prevenção a incêndios florestais, atuando assim nas causas, evitando que os incêndios se iniciem.

Palavras-chave: Educação Ambiental. Incêndio Florestal. Prevenção.

\section{Resumen}

Este trabajo tuvo como objetivo mostrar la importancia de la formación de una conciencia ambiental en la población, a través de la educación, buscando la prevención contra los incendios forestales. Se realizó una investigación bibliográfica, demostrando a través de datos estadísticos que gran parte de los incendios forestales ocurre por causas humanas, así este artículo pretendió demostrar la utilización de la educación ambiental como herramienta de trabajo para prevención a incendios forestales, actuando asi en las causas, evitando que los incendios se inicien.

Palabras Clave: Educación ambiental. Incendio Forestal. Prevención.

\footnotetext{
${ }^{1}$ Capitão do Corpo de Bombeiros da Polícia Militar do Paraná, Graduação em História, Especialização em Educação Ambiental pela Instituição Faculdade de Educação São Luís e Especialização em Prevenção e Combate a Incêndios Florestais pelo CB/PMPR (CPCIF 2014). E-mail do autor: alexandre.cavalca@bm.pr.gov.br

${ }^{2} 1^{\circ}$ Tenente do Corpo de Bombeiros da Polícia Militar do Paraná, Graduação em Educação Física, Especialização em Educação Ambiental pela Instituição Faculdade de Educação São Luís e Especialização em Prevenção e Combate a Incêndios Florestais pelo CB/PMPR (CPCIF 2014). E-mail da autora: luisiana.guimaraes@gmail.com
} 


\section{INTRODUÇÃO}

Os incêndios florestais são desastres que trazem os mais diversos prejuízos ao meio ambiente e, consequentemente, à sociedade. Afetando os mais variados tipos de formações vegetais, sejam elas plantadas ou naturais, os incêndios florestais trazem os mais variados danos, sejam eles materiais, ambientais ou humanos (SAUSEN e LACRUZ, org, 2015, p. 178), como por exemplo: a destruição de florestas, áreas agrícolas, maquinários e edificações; redução da biodiversidade (fauna e flora), facilitação de processos erosivos, aumento da poluição do ar, perda de vidas, doenças respiratórias, traumatismos causados pelo fogo, pessoas desabrigadas e desalojadas.

Para que um incêndio florestal se inicie é necessária a soma de alguns fatores que darão início ao processo de combustão, segundo Soares e Viana (2007, p. 31), o fogo é o termo aplicado ao fenômeno físico resultante de uma rápida combinação entre o oxigênio e uma substância combustível (madeira, por exemplo), com produção de calor, luz e, normalmente chamas, ou seja, o fogo, ou mais precisamente a combustão, é uma rápida reação química de oxidação que necessita de três elementos para se iniciar: combustível, comburente (oxigênio) e calor (fonte de ignição), formando o chamado triângulo do fogo (SOARES e VIANA, 2007, p.34).

Portanto, para impedir o início de um foco de incêndio, deve-se tomar medidas preventivas que eliminem um dos elementos do triângulo do fogo, porém, como nos ambientes florestais é impraticável a remoção de todo material combustível e comburente, a educação da população visando o controle das fontes de ignição e os riscos provenientes dos incêndios florestais, torna-se importante ferramenta para a prevenção dos incêndios florestais.

O objetivo principal deste trabalho é mostrar a importância da formação de uma consciência ambiental na população, através da educação, visando a prevenção contra os incêndios florestais. Através da realização de pesquisa bibliográfica, demonstrando através de dados estatísticos que grande parte dos incêndios florestais ocorre por causas humanas, este artigo visa demonstrar a utilização da educação 
ambiental como ferramenta de trabalho preventivo que atua nas causas ao invés das consequências.

\title{
DESENVOLVIMENTO
}

\section{Incêndio florestal}

O incêndio florestal é considerado um desastre natural climatológico, caracterizado pela propagação de fogo sem controle em qualquer tipo de vegetação, situada ou não em áreas legalmente protegidas, conforme a Codificação Brasileira de Desastres, (BRASIL, 2012)

Segundo Soares, Batista e Nunes (2008, p. 4), o incêndio florestal pode ser definido como a combustão não controlada que se propaga livremente consumindo os combustíveis naturais de uma floresta, tais como: o "litter", gramíneas, folhas, tocos e galhos mortos e até mesmo a vegetação viva, dependendo da intensidade. Soares, Batista e Nunes, (2008, p. 4) ainda afirma que:

\begin{abstract}
A principal característica de um incêndio florestal é não estar confinado e se propagar livremente. É um fogo que queima livremente, respondendo às variações do ambiente. Devido às chances de combinações dos combustíveis naturais, clima e topografia, esse fogo pode permanecer somente como pequeno ponto de combustão lenta ou pode rapidamente se desenvolver num fogo de grandes proporções. Nos dois casos está respondendo livremente ao ambiente local. (SOARES, BATISTA e NUNES. 2008, p. 4)
\end{abstract}

Apesar de não ser ideal a utilização do termo "incêndio florestal", o mesmo é muitas vezes generalizado para definir incêndios em outros tipos de vegetação, como campos, pradarias, cerrado, capoeiras, áreas de cultivos agrícolas. No entanto todo incêndio em vegetação pode ser definido como "incêndio florestal", visto que sua classificação não se baseia na estrutura vegetal do bioma, mas no grau de envolvimento de cada extrato do combustível vegetal, desde o solo mineral até o topo das árvores. Com isso, Soares e Batista 2007, p. 59, classificam os incêndios florestais em três tipos: 
Incêndios superficiais: (...) propagam-se na superfície do piso da floresta, queimando os restos vegetais não decompostos, tais como, folhas e galhos caídos, gramíneas, arbustos, enfim, todo material combustível até cerca de $1,80 \mathrm{~m}$ de altura.

Incêndios subterrâneos: (...) propagam-se através das camadas de húmus ou turfa existentes sobre o solo mineral e abaixo do piso florestal.

Incêndios de copa: (...) caracterizam-se pela propagação do fogo através das copas das árvores, independentemente do fogo superficial (...) acima de 1,80 $\mathrm{m}$ de altura.

(...) Finalmente, deve-se mencionar que os três tipos de incêndio descritos podem, e na prática muitas vezes acontece dependendo das condições existentes, ocorrerem simultaneamente, ou nas duas combinações possíveis, a saber, superficial/subterrâneo ou superficial/copa.

Figura 1 - Classificação dos incêndios florestais

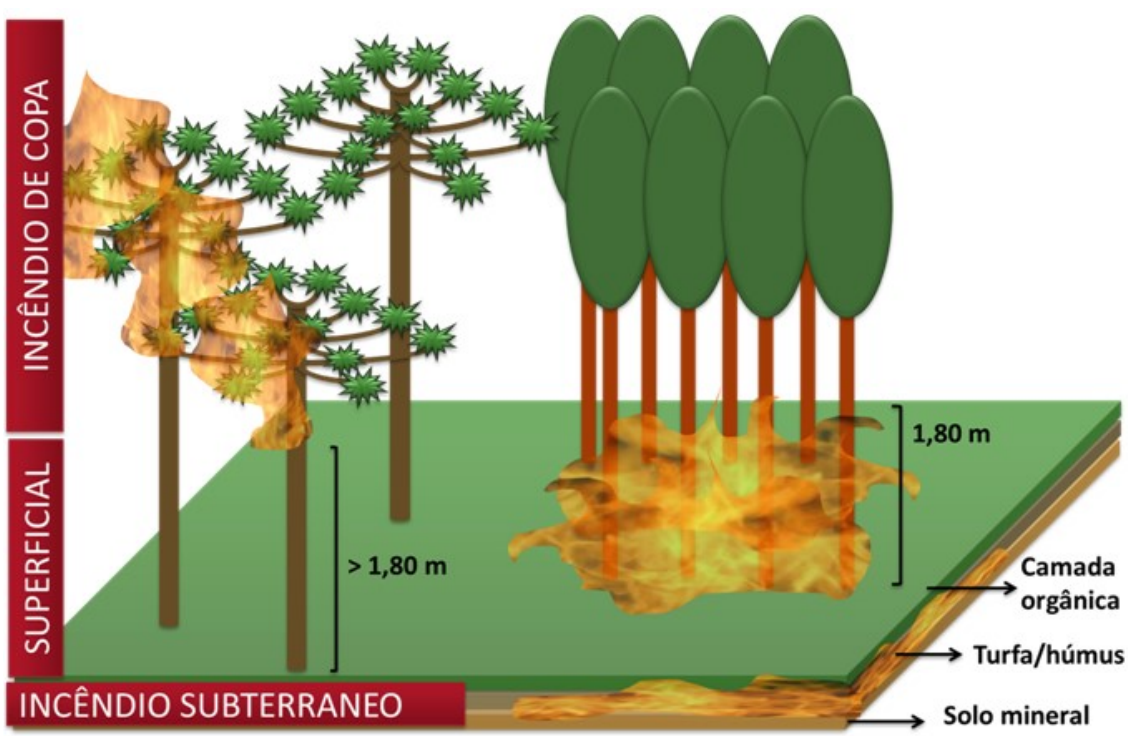

Fonte: BARBOSA, 2011.

Figura 2 - Fotografias de incêndios demonstrando a classificação dos incêndios florestais
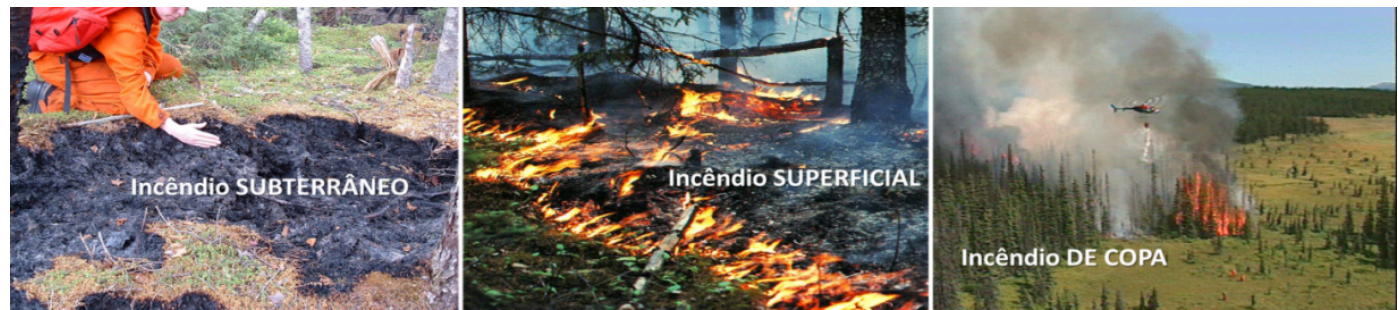

Fonte: BARBOSA, 2011 


\section{Danos causados pelos incêndios florestais}

Como um tipo de desastre natural, o incêndio florestal apresenta como conseqüência a criação de danos materiais, ambientais e pessoais. Em virtude de o fogo ser um fenômeno natural com uma vasta capacidade de transformação do meio e um forte agente transformador da paisagem, pode modificar o ambiente natural causando mudanças na comunidade da fauna e da flora Soares, Batista e Nunes (2009, p. 157), assim como alterações do meio como solo e o ar atmosférico. Segundo Soares, Batista e Nunes $(2009$, p . 1) o fogo é um dos agentes principais de causadores de danos às florestas, e Soares e Batista (2007, p. 91) ainda afirma que "O calor liberado pelo fogo é o responsável primário pelo efeitos imediatos sobre as plantas, animais e solo".

CASTRO (2003, p. 74) apresenta os principais efeitos dos incêndios florestais nos ecossistemas, classificando-os como geradores de danos materiais e danos ambientais:

\footnotetext{
Os incêndios florestais causam danos materiais ao:

- destruírem as árvores em fase de crescimento ou em fase de utilização comercial, reduzindo a produção de madeira, celulose, essências florestais e outros insumos;

- reduzirem a fertilidade do solo, como conseqüência da destruição da matéria orgânica reciclável, obrigando a um maior consumo de fertilizantes; reduzirem a resistência das árvores ao ataque de pragas, obrigando a um maior consumo de praguicidas.

Os incêndios florestais causam danos ambientais:

- reduzindo a biodiversidade;

- alterando drasticamente os biótipos, reduzindo as possibilidades de desenvolvimento equilibrado da fauna silvestre;

- facilitando os processos erosivos; - reduzindo a proteção dos olhos d'água e nascentes.

Os desastres florestais são causa de:

- perdas humanas e traumatismos provocados pelo fogo ou por confusões;

- desabrigados e desalmados;

- redução das oportunidades de trabalho relacionadas com o manejo florestal.
}

Contudo, nem sempre essas modificações causadas pelo fogo são prejudiciais às florestas, existem ecossistemas no planeta que se beneficiam dele, que são os chamados ecossistemas dependentes do fogo, conforme explica Soares, Viana e Nunes (2009, p. 226) "o fogo é essencial e as espécies evoluíram adaptações para responder positivamente ao fogo. A ausência do fogo nestes ecossistemas pode gerar perdas de 
espécies, habitats e identidade de paisagem." Há também, os ecossistemas que são sensíveis ao fogo, que, por outro lado, são prejudicados pela ação do fogo.

Além disso, atualmente, a paisagem tem-se modificado pela ação antrópica, deixando mesmo os ecossistemas dependentes do fogo mais vulneráveis a ação do fogo. Conforme afirma Cardoso e Vasconcellos (2015, p.28), dependendo da intensidade e freqüência de ocorrência, o fogo pode provocar desde leves alterações na composição florística e estrutura dos ecossistemas até a sua total destruição.

De acordo com Soares, Batista e Nunes $(2009$, p. 134) os efeitos do fogo sobre a fauna são comumente divididos em:

\footnotetext{
- Efeitos Diretos ou imediatos - relacionado a atitude dos animais frente ao fogo, mortalidade, lesões, intoxicações por fumaça e deslocamentos. - Efeitos Indiretos ou de longo prazo - são determinados pela mudança do habitat, que influenciam a alimentação, o deslocamento, a reprodução e a disponibilidade de abrigo.
}

Os incêndios em áreas de vegetação nativa afetam a fauna silvestre de maneira geral, tendo consequências positivas para determinadas espécies e negativas para outras espécies que geralmente possuem maiores exigências ecológicas. (SOARES, BATISTA e NUNES, 2009, p. 175).

Assim o fogo certamente modifica bastante os ambientes para as espécies de maneira geral, podendo comprometer espécies com menos plasticidade ecológica. A longo prazo, os efeitos destas queimadas talvez não apresentem significativa alteração na fauna silvestre de uma região, porém os efeitos imediatos, dependendo da amplitude do incêndio podem levar algumas espécies à extinção local. (SOARES, BATISTA e NUNES, 2011, p.176)

\section{Principais causas dos incêndios florestais}

As causas dos incêndios florestais podem ter diversas origens, de acordo com Tetto, Batista e Soares (2011, p. 27):

A origem do incêndio florestal está relacionada ao analfabetismo ambiental (desconhecimento do individuo das conseqüências de seus atos), à ocorrência de um incidente (fogueiras mal apagadas, rompimentos de alta tensão), aos aspectos culturais (rituais religiosos, conflitos rurais, balões de festa junina, piromania entre outros), os fenômenos naturais (raios), ao extrativismo (caça, pesca,retirada de madeira, coleta de frutos, entre outros) e a política agrária (pela forma de estimulo as formas de produção que utilizem as queimadas).(TETTO; BATISTA e SOARES, 2011, p. 27) 
Assim nota-se que em sua maioria os incêndios florestais são provocados por causas humanas, intencional ou não intencionalmente.

Segundo Tetto, Batista e Soares (2011, p. 27 e 28), a Organização Mundial das Nações para agricultura e alimentação (FAO), com o objetivo de padronizar e analisar as causas dos incêndios florestais, recomenda a utilização de oito categorias de causa: Raios; Incendiários; Queimas para limpeza; Fumantes; Operações florestais; Fogos de recreação; Estradas de ferro; E diversos (ocorrências não enquadradas anteriormente por conterem poucos incidentes - balões de festa junina, acidente de avião, entre outros).

Tabela 1 - Causas prováveis de incêndios de 1983 a 2002 e relação com o número de incêndios.

\begin{tabular}{|l|r|r|r|r|r|r||}
\hline \multirow{2}{*}{\multicolumn{1}{c|}{ Causas }} & \multicolumn{2}{c|}{$1983 \mathrm{a} 1987$} & \multicolumn{2}{c|}{$1994 \mathrm{a} 1997$} & \multicolumn{2}{c||}{$1998 \mathrm{a} 2002$} \\
\cline { 2 - 7 } & \multicolumn{1}{|c|}{$\mathrm{N}^{\mathbf{0}}$} & \multicolumn{1}{c|}{$\%$} & \multicolumn{1}{c|}{$\mathrm{N}^{\mathbf{0}}$} & \multicolumn{1}{c|}{$\%$} & \multicolumn{1}{c|}{$\mathrm{N}^{\circ}$} & \multicolumn{1}{c||}{$\%$} \\
\hline Diversos & 104 & 8,0 & 42 & 6,0 & 730 & 11,0 \\
\hline Estradas de Ferro & 12 & 0,9 & 11 & 1,6 & 7 & 0,1 \\
\hline Fogos de Recreação & 141 & 10,9 & 23 & 3,3 & 19 & 0,3 \\
\hline Fumantes & 104 & 8,0 & 43 & 6,1 & 109 & 1,7 \\
\hline Incendiários & 386 & 29,8 & 396 & 56,6 & 4579 & 69,1 \\
\hline Operações Florestais & 87 & 6,7 & 21 & 3,0 & 205 & 3,1 \\
\hline Queimas para Limpeza & 435 & 33,6 & 155 & 22,1 & 870 & 13,1 \\
\hline Raios & 27 & 2,1 & 9 & 1,3 & 103 & 1,6 \\
\hline \hline Subtotal & 1296 & 100,0 & 700 & 100,0 & 6622 & 100,00 \\
\hline Não determinada & 458 & - & 1257 & - & 12755 & - \\
\hline Total & 1754 & - & 1957 & - & 19377 & - \\
\hline
\end{tabular}

Fonte: Soares, Batista e Nunes (2009, p. 12)

Tabela 2 - Causas prováveis de incêndios de 1983 a 2002 e relação com a área queimada.

\begin{tabular}{||l|r|r|r|r|r|r||}
\hline \multirow{2}{*}{\multicolumn{1}{c|}{ Causa }} & \multicolumn{2}{c|}{1983 a 1987} & \multicolumn{2}{c|}{1994 a 1997} & \multicolumn{2}{c|}{1998 a 2002} \\
\cline { 2 - 7 } & \multicolumn{1}{c|}{ ha } & \multicolumn{1}{c|}{ ha } & \multicolumn{1}{c|}{$\%$} & \multicolumn{1}{c|}{ ha } & \multicolumn{1}{c|}{$\%$} \\
\hline Diversos & 4052,0 & 4,4 & 7930,1 & 3,7 & 1594,1 & 8,5 \\
\hline Estradas de Ferro & 496,2 & 0,5 & 20,9 & 0,0 & 13,8 & 0,1 \\
\hline Fogos de Recreação & 10778,2 & 11,6 & 2244,3 & 1,0 & 14,6 & 0,1 \\
\hline Fumantes & 2648,8 & 2,9 & 1987,6 & 0,9 & 218,5 & 1,2 \\
\hline Incendiários & 13589,1 & 14,7 & 42623,9 & 19,8 & 12240,5 & 65,3 \\
\hline Operações Florestais & 1875,2 & 2,0 & 467,7 & 0,2 & 148,5 & 0,8 \\
\hline Queimas para Limpeza & 59064,1 & 63,7 & 159633,3 & 74,1 & 4434,3 & 23,6 \\
\hline Raios & 175,4 & 0,2 & 592,4 & 0,3 & 70,5 & 0,4 \\
\hline Subtotal & 92679,0 & 100,0 & 215500,1 & 100,0 & 18738,8 & 100,0 \\
\hline Não determinada & 41428,3 & - & 50445,8 & - & 67000,4 & - \\
\hline \hline Total & 134107,3 & - & 265946,0 & - & 85735,2 & - \\
\hline
\end{tabular}

Fonte: Soares, Batista e Nunes (2009, p. 13)

Analisando a Tabela 1 e de acordo com Soares, Batista e Nunes (2009, p. 8) no período de 1983 à 1987, o principal grupo de causa para incêndios florestais era "queima para limpeza", seguida de "incendiários". Nos períodos seguintes houve uma inversão com os "incendiários" sendo identificados como a principal causa e a "Queima para limpeza" a segunda.

A Tabela 2 apresenta as causas para incêndios florestais, sendo os provocados pelos "incendiários" também ocupam o primeiro lugar em relação a dimensão da área 
queimada, os quais são iniciados durante todo o ano, independente das condições não serem favoráveis à propagação do fogo.

Segundo o mesmo autor estas causas podem ser explicadas por problemas sociais, como desemprego, disputas de posse da terra e pressão urbana, e esta tendência vêm ocorrendo não apenas no Brasil mas em várias partes do mundo, como o exemplo da Europa. (SOARES, BATISTA e NUNES, 2009, p. 08).

Atualmente há uma crescente preocupação com o aumento dos incêndios causados pelos incendiários em todo o mundo (SOARES, 2004). Na Europa, de maneira geral, $50 \%$ dos incêndios têm sido causados por incendiários. Os incendiários ocupam o primeiro lugar nos números de incêndios registrados na África do Sul, nos Estados Unidos, na Espanha, na Grécia e na Itália. (SANTOS, SOARES E BATISTA, 2006)

Identificar as causas dos incêndios é de suma importância pois permite conhecer os principais grupos , direcionando ações preventivas as agentes causadores com maiores índices, mas para isso é necessário ser realizado uma perícia identificando ponto de origem do fogo , e assim consequentemente o agente causador (SOARES, BATISTA e NUNES, 2009, p. 09). Os mesmos autores ressaltam que:

A causa mais difícil de identificar é o grupo "incendiário", pois quem coloca fogo propositalmente não quer deixar vestígio que o possa identificar (...) a falta de um indício da causa do fogo é um sinal de que ele provavelmente foi provocado por um incendiário. (SOARES, BATISTA e NUNES, 2009, p. 09)

\section{Educação Ambiental}

A educação é um dos melhores meios para a propagação do conhecimento, e um direito de toda criança, adolescente e jovem, sendo um dever da família, da sociedade e do Estado (Brasil, 1988, CF Art. 227). No âmbito da preservação do meio ambiente, a educação ambiental foi citada pela primeira vez em uma Constituição Federal Brasileira em 1988 (PEDRINI Org, 2011, p. 26) e é apresentada como um direito, a fim de garantir a educação ambiental e conscientização publica para a manutenção do meio ambiente, conforme Art. 225, §1 ${ }^{\circ}$, Inciso VI da Constituição Federal (1988):

Art. 225. Todos têm direito ao meio ambiente ecologicamente equilibrado, bem de uso comum do povo e essencial à sadia qualidade de 
vida, impondo-se ao Poder Público e à coletividade o dever de defendê-lo e preservá- lo para as presentes e futuras gerações. Público:(...)

$\S 1^{\circ}$ Para assegurar a efetividade desse direito, incumbe ao Poder

VI - promover a educação ambiental em todos os níveis de ensino e a conscientização pública para a preservação do meio ambiente; (BRASIL, 1988) (grifo meu)

Atendendo os ditames da carta magna brasileira (Constituição Federal), foi criada, em 1999, a Política Nacional de Educação Ambiental, através da Lei no 9795/1999, a qual define a educação ambiental como (BRASIL, Política nacional de educação ambiental, lei no 9795/1999, art. $1^{\circ}$ ):

(...) os processos por meio dos quais o indivíduo e a coletividade constroem valores sociais, conhecimentos, habilidades, atitudes e competências voltadas para a conservação do meio ambiente, bem de uso comum do povo, essencial à sadia qualidade de vida e sua sustentabilidade. (...)

Art. 13. Entendem-se por educação ambiental não-formal as ações e práticas educativas voltadas à sensibilização da coletividade sobre as questões ambientais e à sua organização e participação na defesa da qualidade do meio ambiente.

Parágrafo único. O Poder Público, em níveis federal, estadual e municipal, incentivará:

I - a difusão, por intermédio dos meios de comunicação de massa, em espaços nobres, de programas e campanhas educativas, e de informações acerca de temas relacionados ao meio ambiente; (grifo meu)

Assim, através da normativa da Política Nacional de Educação Ambiental, o Poder Público, a nível municipal, estadual e federal, ficou com a responsabilidade de incentivar a educação ambiental não formal através da difusão em meios de comunicação de massa com a veiculação de programas e campanhas educativas, assim como informações relacionadas com o meio ambiente, sensibilizando a coletividade na defesa da qualidade do meio ambiente.

Através da promoção da Educação Ambiental, o cidadão começa a fazer uso do meio ambiente de maneira sustentável. De acordo com Soares, Batista e Nunes (2009, p. 233):

A educação ambiental é um conjunto de atividades e idéias que levam o homem a conhecer e utilizar recursos do ambiente de modo sustentado. Ela deve ser entendida como o processo de formação social orientado para o desenvolvimento da consciência crítica sobre a questão ambiental (grifo meu) 


\section{Educação ambiental e a prevenção de incêndios florestais}

A prevenção de incêndios atua com o objetivo de diminuir ou eliminar as chances de um incêndio florestal começar e caso não seja possível evitar seu inicio que ocorra a limitação de sua propagação. Soares e Batista (2007, p. 165) afirmam que a prevenção dos incêndios florestais envolve dois níveis de atividades. O primeiro deles é a prevenção dos incêndios de causas humanas buscando através da educação da população, de uma legislação ambiental consolidada e medidas punitivas, evitar a primeira fagulha, ou seja, que o fogo se inicie. O outro nível compreende o uso de técnicas adequadas para manejo do combustível florestal, impedindo ou dificultando a propagação dos incêndios que não foram evitados.

Soares e Batista (2007, p. 166), sobre a prevenção de incêndios florestais, ainda expõem que:

\footnotetext{
A prevenção de incêndios age basicamente em dois lados do triangulo do fogo: ignição e combustível.

As causas dos incêndios são as fontes da ignição. Para atuar sobre esse lado do triangulo é necessária a identificação precisa das causas. Através desse conhecimento é possível criar programas de educação e informação para o publico em geral e /ou para grupos específicos, agindo diretamente sobre a raiz do problema. (grifo meu)
}

Portanto, a melhor forma de se proteger a floresta contra o fogo é com a prevenção, considerando que os dados estatísticos demonstram que a maioria dos incêndios florestais ocorre por causas humanas, pode-se inferir que, teoricamente, eles são em sua maioria, evitáveis.

Desta forma a falta de conscientização da população é o primeiro problema a ser enfrentado com relação à prevenção de incêndios florestais, pois se todas as pessoas que utilizam as áreas florestais fossem bem informadas sobre o potencial destrutivo dos incêndios florestais e como evitá-los, apenas um pequeno número de incêndios ocorreria anualmente. Com isso, a educação sobre o fogo pode ser uma forma muito eficaz para que as comunidades sejam envolvidas em programas de manejo do fogo, utilizando-o de forma cuidadosa e atenta às políticas e as leis, por tal motivo, a educação da população 
deve ser a primeira iniciativa na prevenção de incêndios florestais (SOARES e BATISTA, 2007, p. 172)

Ramos, (1995) enfatiza a importância da educação ambiental da população como forma de prevenção dos incêndios florestais:

\begin{abstract}
Atualmente, no Brasil, mais de $90 \%$ dos Incêndios Florestais são provocados pelo homem. A prevenção de incêndios florestais está intimamente associada ao nível de conscientização e sensibilidade da comunidade, a qual deve estar plenamente ciente da necessidade de se preservar as florestas, devendo-se, portanto, evitar condições propícias à ocorrência de incêndios florestais. $O$ esclarecimento, tanto do público rural quanto urbano, como aos perigos, impactos e prejuízos causados pelo uso indiscriminado e irresponsável do fogo em áreas rurais e florestais deverá ser insistentemente perseguido através de campanhas educativas, palestras, cursos e outros recursos educacionais, utilizando-se para tanto as estruturas das redes de ensino, das EMATER's e todos os veículos de comunicação disponíveis jornais, rádio, TV etc.). Essas campanhas deverão ter caráter nacional, porém com uma ênfase maior nas regiões onde o problema se apresenta com maior gravidade e nas áreas próximas às Unidades de Conservação. Quanto à duração, elas devem se estender durante todo o ano, intensificando-se durante o período da seca. (RAMOS, 1995) (grifo meu)
\end{abstract}

De acordo com o SENAR (2011, p. 31) há três formas de prevenção e uma delas é a educação da população. Neste contexto que se enquadra a Educação Ambiental, através da conscientização da população das causas e conseqüências ao meio ambiente, para que se entenda a importância da prevenção ao incêndio florestal.

Segundo BARROS, org. (2010, p.100):

A educação preventiva é o controle e remoção de riscos de incêndios florestais persuadindo as pessoas a adotar um comportamento compatível a segurança florestal, objetivando seu próprio bem ou de seus semelhantes. Aos notarmos práticas indevidas tais como abandono de resíduos combustíveis em matas, acampamentos, liberação de resíduos de serrarias, e outros descontroles de riscos, podemos por meio de ação educativa formar uma conscientização no público alvo sobre a importância da floresta e os danos que os incêndios ocasionam a mesma. Para se chegar a tal objetivo deve-se atingir todas as classes de pessoas que possam vir a ocasionar tais incêndios, por meio de uma linguagem clara e objetiva, mostrando porque o incêndio deve ser evitado. 
Revista Científica do Corpo de Bombeiros Militar de Pernambuco

XVIII Seminário Nacional de Bombeiros - Foz do Iguaçu PR

Vol.04 No11 - Edição Especial XVIII SENABOM - ISSN 2359-4829

Versão on-line disponível em: http://www.revistaflammae.com.

Barros, org. (2010, p. 101), também afirma que alguns veículos de comunicação podem ser utilizados na educação da população, são eles: Livros; Cartilhas; Mensagens em televisão e rádio; Painéis; Palestras; e Contato pessoal.

Para elaborar programas voltados a Educação Ambiental, Teto, Batista e Soares (2011, p. 31) recomendam algumas estratégias para a formulação e planejamento de programas de conscientização das pessoas, através da direção dos programas voltados a públicos e comunidades específicas, sendo sensíveis à cultura da sociedade inclusive em relação ao uso tradicional do fogo; o desenvolvimento do programa deverá ser uma parceria entre técnicos em incêndios florestais e profissionais da educação, além disso, instituições de ensino devem ser estimuladas a desenvolverem programas de manejo do fogo apropriados as comunidades.

Um meio de conscientização e prevenção ao incêndio florestal é a instalação da placa de divulgação do grau de risco de incêndios para diversas regiões, que apontam este risco de nulo a extremo, sendo que o nulo significa incêndio florestal improvável e o extremo significa que as características são extremamente favoráveis a ocorrência de incêndios. A utilização deste recurso gera uma conscientização da necessidade de proteger as florestas contra os danos causados pelo fogo.

Figura 3 - Placa indicativa do perigo de incêndio

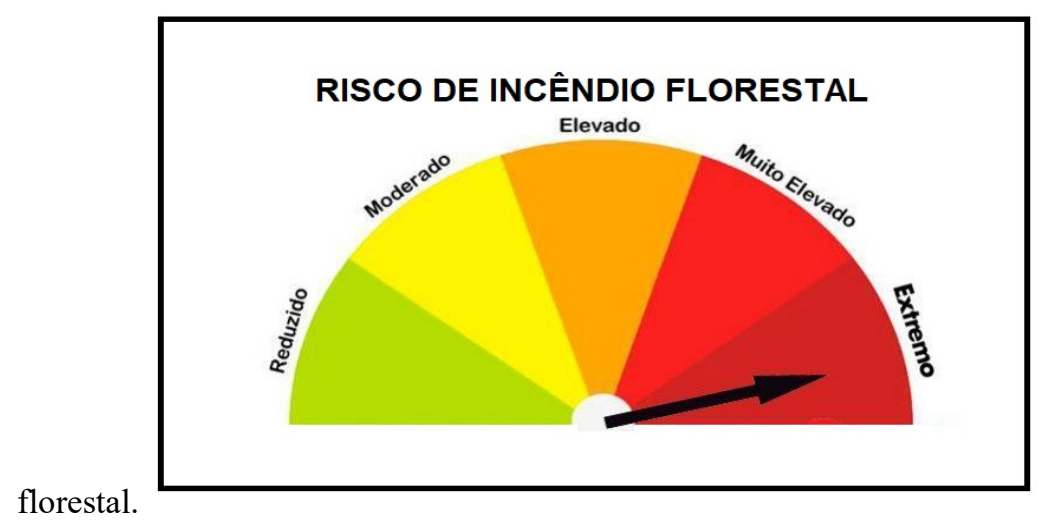

Fonte: Tetto, (2011).

Outra ferramenta na educação ambiental com foco em prevenção de incêndios florestais é a utilização de cartazes educativos para sensibilização das pessoas quanto à prevenção e combate aos incêndios florestais. 
Revista Científica do Corpo de Bombeiros Militar de Pernambuco

XVIII Seminário Nacional de Bombeiros - Foz do Iguaçu PR

Vol.04 No11 - Edição Especial XVIII SENABOM - ISSN 2359-4829

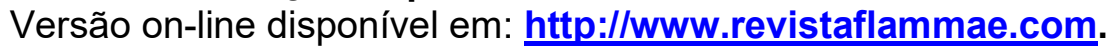

Figura 4 - Cartazes do programa de prevenção de incêndio florestal chamado "Mata Viva" da Defesa Civil do Estado do Paraná.

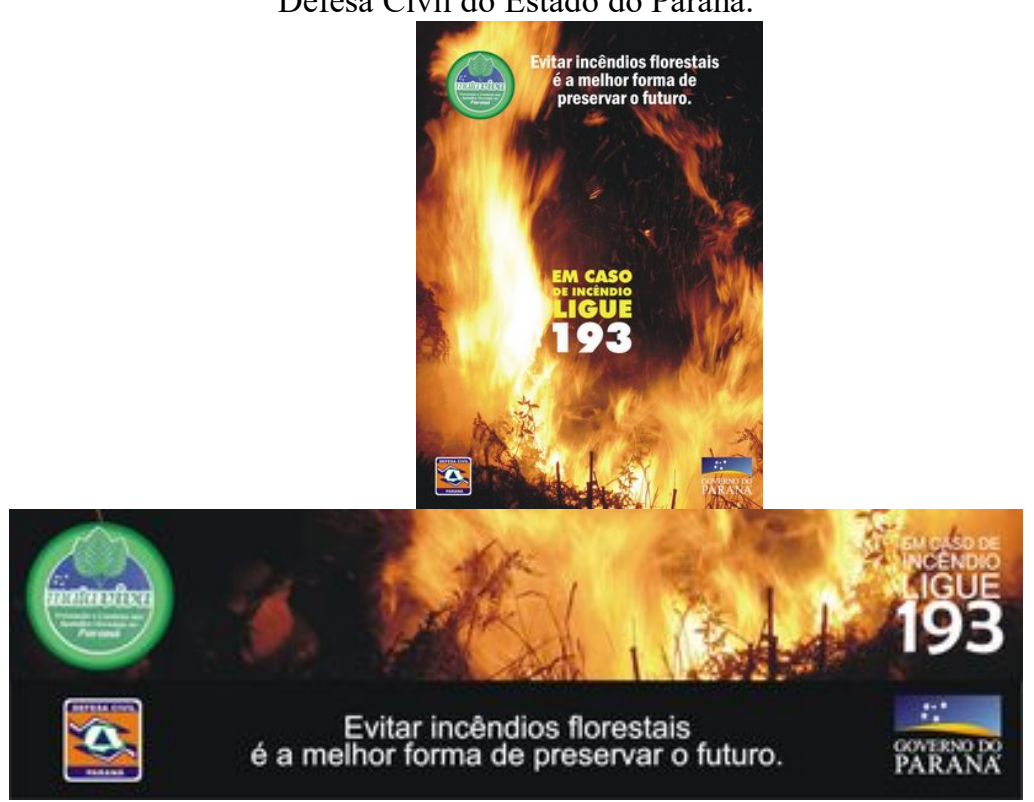

Fonte: Paraná. (2008)

Figura 5 - folder da operação corta fogo do Estado de São Paulo.

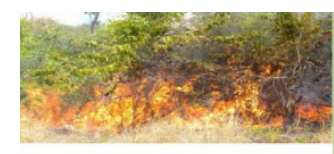

Provocar incêndios florestais crime previsto na Lei de des ambientais, com pena de multa e prisão

Prevenir é melhor do que apagar!

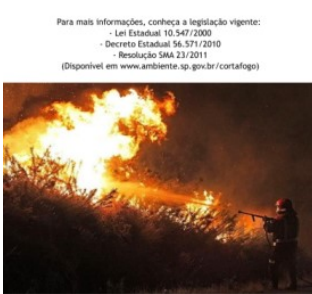

Ao avistar fumaça ou focos de
incênnio, contate imediatamente o Corpo de Bombeiros:

LIGUE 193

Você pode ajudar a salvar vidas!

\section{TELFFones UंTers}

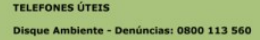

Disque Ambiente - Denúncias: 00000

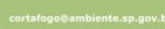

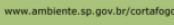
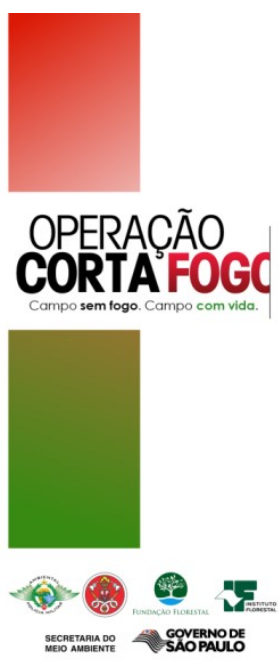

Fonte: São Paulo. (2016)

As Figuras 4 e 5 apresentam modelos de folder e cartazes utilizados em campanhas de sensibilização da população com relação ao uso do fogo no Estado do Paraná (campanha Mata Viva) e São Paulo (campanha Operação Corta Fogo), com intuito de diminuir a incidência de incêndios florestais em ambas unidades da federação. 
Revista Científica do Corpo de Bombeiros Militar de Pernambuco

XVIII Seminário Nacional de Bombeiros - Foz do Iguaçu PR

Vol.04 N011 - Edição Especial XVIII SENABOM - ISSN 2359-4829

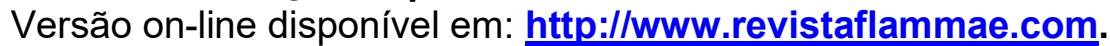

Tais campanhas se destacam pelo envolvimento de diversos órgãos governamentais e da sociedade civil organizada, demonstrando a importância da educação ambiental da população na luta contra os incêndios florestais.

Figura 6 - Gibi da Operação Corta Fogo - promovida pelo Governo do Estado de São Paulo.
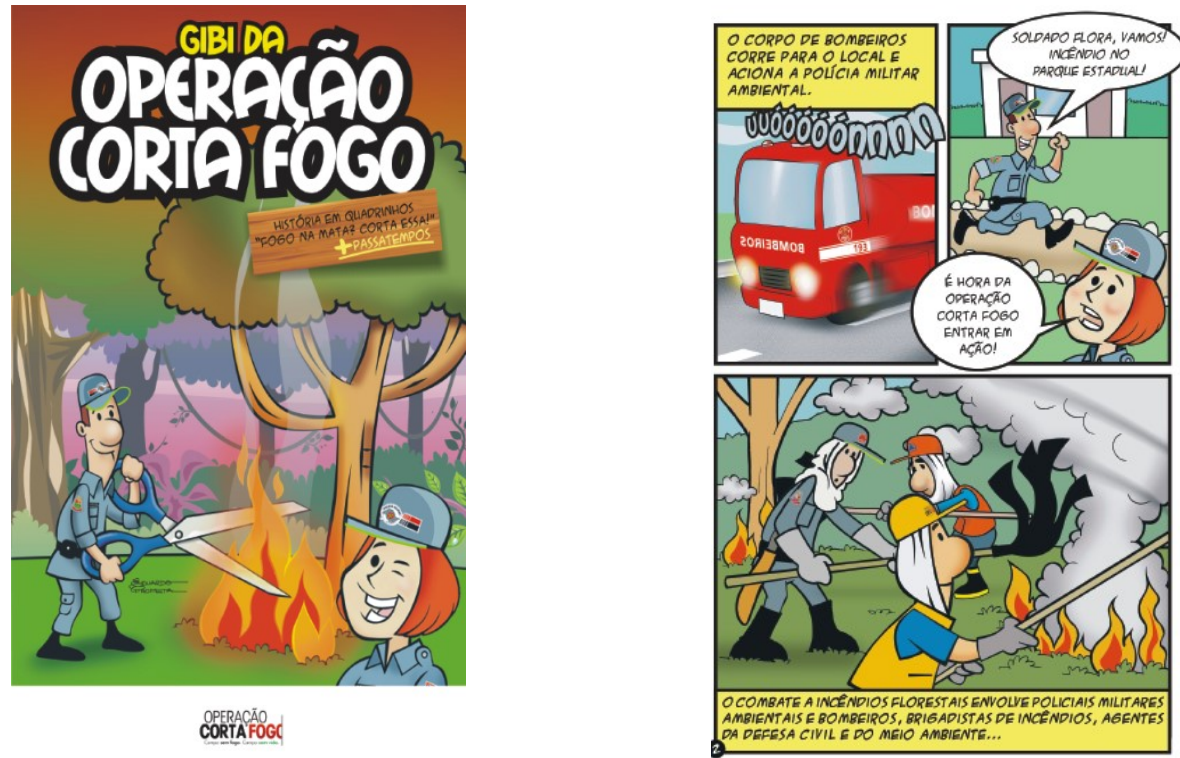

Fonte: São Paulo. (2016)

A Figura 6 demonstra uma iniciativa do Estado de São Paulo, promovida pela campanha "Operação Corta Fogo", para fomentar a questão da educação ambiental, conscientizando as crianças para que entendam o incêndio ambiental e suas graves conseqüências para o meio ambiente e, consequentemente, para todas as pessoas.

O gibi da campanha "Operação Corta Fogo" apresenta as crianças, através do lúdico, importantes lições sobre o tema da educação ambiental, relacionada com a prevenção dos incêndios florestais. O referido gibi traz de maneira didática a problemática dos incêndios florestais, as formas de se evitá-lo e como cada criança pode fazer para auxiliar na prevenção dos incêndios florestais, incentivando a criança a enxergar-se como parte integrante do meio ambiente em que se vive, como sujeito ativo de sua sociedade, entendendo as questões da proteção ambiental como ferramenta essencial para a cidadania. 


\section{CONCLUSÕES}

A ocorrência, no Brasil, de incêndios florestais é uma realidade e tem causado sérios danos ambientais e econômicos ao país, portanto existe a necessidade de se estabelecer a educação ambiental como meio de conscientização da população na prevenção a esses incêndios.

Como explicitado no presente artigo, a principal causa dos incêndios serem iniciados é por ação humana, em especial por incendiários. Neste contexto a educação ambiental torna-se um meio viável para a conscientização da população na prevenção aos incêndios florestais, porém a grande dificuldade é de alcançar pessoas de todas as classes sociais, responsáveis por ocorrências de incêndios florestais, através de uma comunicação simples e objetiva que tenha como foco mostrar como e porque evitar o fogo na floresta.

Para atingir a maior parte das pessoas, as campanhas de conscientização precisam ser idealizadas para públicos diversos, como jovens e adultos, através de folders, cartazes e placa de indicação de risco de incêndios florestais, assim como cartilhas e gibis educativos para que crianças e adolescentes também se conscientizem da importância da preservação do meio ambiente através da prevenção aos incêndios florestais.

Através de campanhas, a educação ambiental pode agir estimulando nos indivíduos a percepção de que são parte integrante da natureza, e tem papel importante na proteção ao meio ambiente, conscientizando a todos que têm direitos e deveres perante o meio ambiente em que se vive.

\section{REFERÊNCIAS}

BARBOSA, Ana Carolina Maioli C. Aula 3 - Classificação dos Incêndios Florestais. Disponível em: $<$ http://gef152.blogspot.com.br/2011/10/aula-3-classificac ao-dosincendios.html $>$ Acesso em 10 de setembro de 2017. 
Revista Científica do Corpo de Bombeiros Militar de Pernambuco XVIII Seminário Nacional de Bombeiros - Foz do Iguaçu PR

Vol.04 N011 - Edição Especial XVIII SENABOM - ISSN 2359-4829

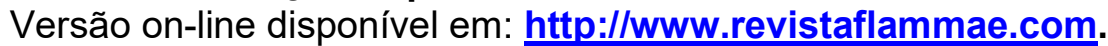

BARROS, Edemilson de (Org). Manual de Prevenção e combate a incêndios florestais. 3. Ed. Curitiba: Corpo de Bombeiros da PMPR, 2010.

BRASIL. Constituição da República Federativa do Brasil. Brasília: Centro Gráfico, 1988.

BRASIL. Ministério da Integração Nacional. Secretaria Nacional de Defesa Civil. Instrução Normativa $\mathrm{n}^{\circ}$ 01, de 24 de agosto de 2012. Diário Oficial da Uniião, n. 169, seção 1, p. 30, 30 ago. 2012. Disponível em: http://www.mi.gov.br/defesacivil/ legislacoes. Acesso em: 28 de agosto de 2017.

CASTRO, Antônio Luiz Coimbra de. Manual de desastres: Volume I - desastres naturais. Brasília: 2003.

CARDOSO, Jurandy Bran Nogueira; VASCONCELLOS, Rafael L. F. Floresta com araucária: composição florística e biota do solo. Piracicaba: FEALQ, 2015.

PARANÁ. Coordenadoria Estadual de Proteção e Defesa Civil. Campanha mata viva 2008. Curitiba, PR, 2008. Disponível em $<$ http://www.defesacivil.pr.gov.br/modul es/conteudo/conteudo.php?conteudo=62> Acesso em 10 de setembro de 2017.

PEDRINI, Alexandre de Gusmão (Org.). Educação ambiental: reflexões e práticas contemporâneas. Petrópolis: Vozes, 1997.

RAMOS, Paulo Cesar Mendes. Sistema Nacional de prevenção e combate aos incêndios florestais. In: I Fórum Nacional sobre Incêndios Florestais / III Reunião Conjunta IPEF-FUPEF-SIF, 1995. Anais do... Piracicaba: IPEF-FUPEF-SIF, 1995. Disponível em $<$ http://atividaderural.com.br/artigos/50edf67c3b107.pdf $>$ Acesso em 01 de setembro de 2017.

SANTOS, Juliana Ferreira; SOARES, Ronaldo Viana; BATISTA, Antônio Carlos. Perfil dos Incêndios florestais no Brasil em áreas protegidas no período de 1998 a 2002. Curitba, PR, 2006. Disponível em $<$ http://revistas.ufpr.br/floresta article/view/5510/4040> Acesso em 01 de setembro de 2017.

SAUSEN, Tania Maria; LACRUZ, María Silvia Pardi. Org. Sensoriamento remoto para desastres. São Paulo: Oficina de textos, 2015.

SÃO PAULO, Governo do Estado de São Paulo. Corta fogo. São Paulo, SP, 2016. Disponível em $<$ http://www.ambiente.sp.gov.br/cortafogo/informativos/> Acesso em 13 de setembro de 2017.

SOARES, Ronaldo Viana; BATISTA, Antônio Carlos. Incêndios florestais: controle, efeitos e uso do fogo. Curituba: UFPR, 2007. 
Revista Científica do Corpo de Bombeiros Militar de Pernambuco XVIII Seminário Nacional de Bombeiros - Foz do Iguaçu PR Vol.04 No11 - Edição Especial XVIII SENABOM - ISSN 2359-4829 Versão on-line disponível em: http://www.revistaflammae.com.

SOARES, Ronaldo Viana; BATISTA, Antônio Carlos; NUNES, José Renato Soares. Manual de prevenção e combate a incêndios florestais. 2. Ed. Curitiba: UFPR, 2008.

SOARES, Ronaldo Viana; BATISTA, Antônio Carlos; NUNES, José Renato Soares. Incêndios florestais no Brasil: o estado da arte. Curitiba: UFPR, 2009.

TETTO, Alexandre França; BATISTA, Antônio Carlos; SOARES, Ronaldo Viana. Prevenção e combate aos incêndios florestais. Curitiba: Senar, 2011.

TETTO, A. F.; BATISTA, A. C.; KOCK, R.; LAUTHERT, L. Zoneamento de risco de incêndios florestais para o estado do Paraná, Brasil. In: SIMPÓSIO SULAMERICANO SOBRE CONTROLE DE INCÊNDIOS FLORESTAIS, 5., 2011, Campinas. Anais do... Campinas: FUPEF;SIF/IPEF, 2011, 1 CD-ROM.

m J Cardiol, v. 112, n. 12, p. 1962-7, Dec 152013. 